\title{
Dual- Band Antenna for Wi-Fi and 5G Applications
}

\author{
Suman Nelaturi, A Sarath Raja, Y Rakesh
}

\begin{abstract}
In this communication, a circular patch antenna is reported for dual- band operation based on VIAs. Initially the patch is resonating at single band with Linear Polarization (LP), and the Circular Polarization (CP) is obtained by inserting semi circular cuts at the edges of circular patch. The second band is achieved by loading the vertical metallic VIAs along the circumference of the patch antenna. The reported antenna is working at $2.4 \mathrm{GHz}$ (Wi-Fi) and $3.5 \mathrm{GHz}(5 \mathrm{G})$ bands with Return Loss Band Width (RLBW) of $4.83 \%$ and $10.37 \%$ respectively. The Axial Ratio (AR) bandwidth at $5 G$ band is $2.38 \%$ (3.31- 3.39 GHz).
\end{abstract} Ratio

Keywords: circular patch, Metamaterials, VIAs, CP, Axial

\section{INTRODUCTION}

The patch antennas are useful in wireless communications because of their low weight, low cost and easy fabrication characteristics [1]. The patch antenna which can resonate at multiple frequencies is the very much useful component for modern electronic gadgets. The dual-band antenna with good impedance bandwidth and good gain is achieved by using metamaterials [2]. The dual- band patch antennas are designed based on CSRR, Mushroom Unit cell and VIAs [37], which are suffering from bandwidth and gain. The impedance bandwidth at both the bands is improved in this design. In this article, a circular patch antenna is demonstrated. The two bands are obtained by loading VIAs. The $\mathrm{cp}$ at higher band is obtained by removing the sides of the circular patch. The reported structure is simulated in HFSS software

\section{STRUCTURE OF WI-FI AND 5G ANTENNA}

The structure is reported in figure 1. Rogers RT/Duroid with permittivity 2.2 , thickness $3.2 \mathrm{~mm}$ is used. semi circular cuts are inserted at the edges of the patch for $\mathrm{cp}$ at patch mode band and the vertical VIAs are inserted for second band.

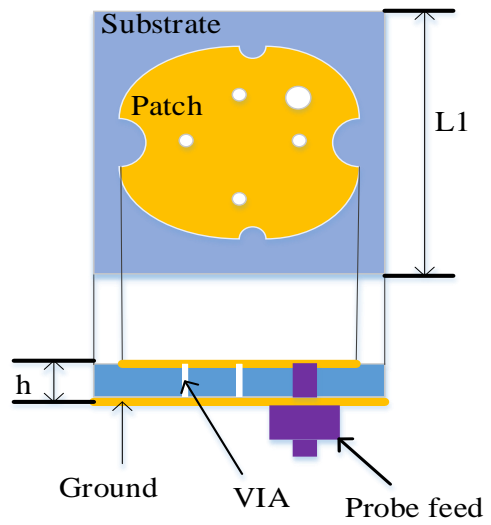

Figure 1 structure of the antenna
The design procedure is shown in figure 2 and is as follows. Initially circular patch antenna Ante 1 is working at $2.8 \mathrm{GHz}$ with LP. Later the edges are loaded with semi circular curves for cp to obtain Ant2. Ante3 is occurred by loading VIAs into Ante2 for dual band operation with LP at both the bands. Finally, proposed antenna Ante4 is achieved by replacing the edges of Ante3 with semi circular curves.

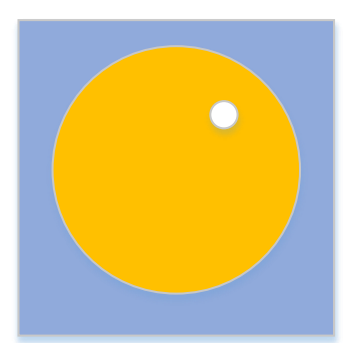

Ante 1

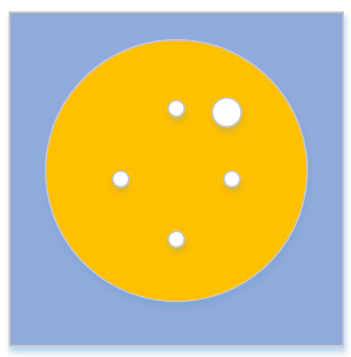

Ante3

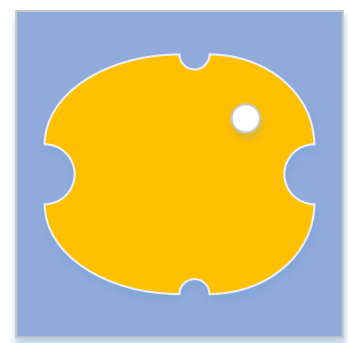

Ante2

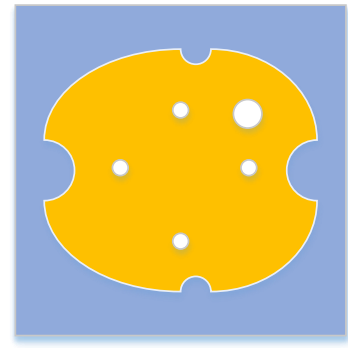

Ante4
Figure2 Design procedure

\section{RESULT DESCRIPTION}

The simulated RL characteristics of four antennas are given in figure3. The AR graph is shown in figure4. Radiation patterns at both the bands are displayed in figure 5. Gain plot is drawn in figure 6 .

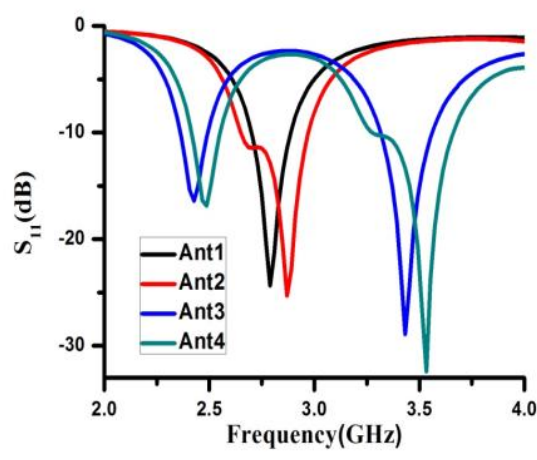

Figure 3 RL characteristics $f$ the antennas 


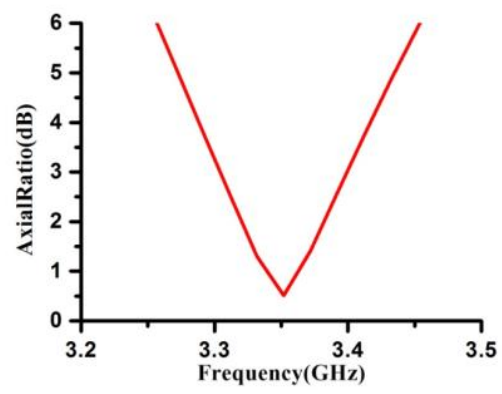

Figure 4 AR characteristics

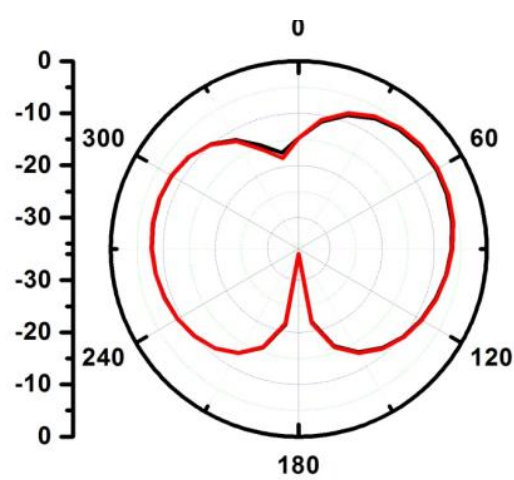

(a)

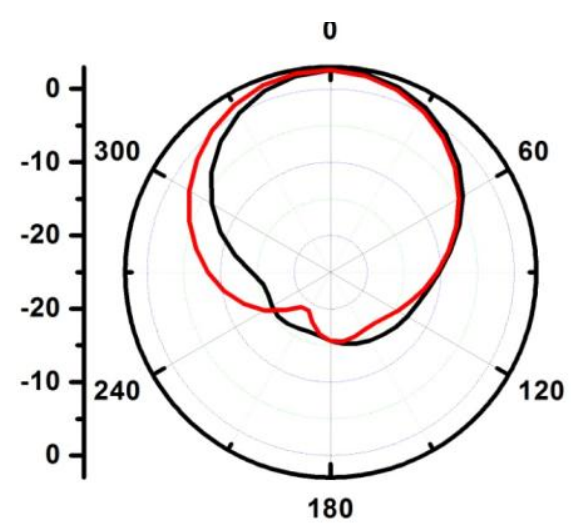

(b)

Figure 5 radiation patterns at (a) Wi-Fi (b) 5 G

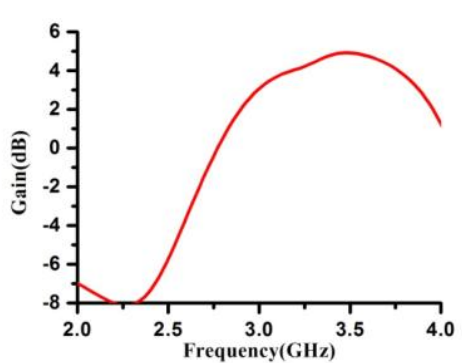

Microwaves, Antennas \& Propagation, vol.7, no.4, pp. 259-267, 2013.

6. Cao, Wen-Quan, "Compact dual-band dual-mode circular patch antenna with broadband unidirectional linearly polarized and omnidirectional circularly polarized characteristics," IET Microwaves, Antennas \& Propagation, vol.10, no.2, pp.223-229, 2016.

7. Cao, Wen-quan, Qian-qian Wang, Bang-ning Zhang, and Wei Hong, "Capacitive probe-fed compact dual-band dual-mode dualpolarization microstrip antenna with broadened bandwidth," IET Microwaves, Antennas \& Propagation, vol.11, no.7 pp.1003-1008, 2017.

Figure 6 Gain plot

\section{CONCLUSIONS}

In this article, patch antenna is described for Wi-Fi and $5 \mathrm{G}$ applications. The vertical VIAs are loaded along the circumference of the circular patch. The RL bandwidth is $4.83 \%(2.42-2.54 \mathrm{GHz})$ at lower band and is $10.37 \%$ at upper band respectively. The AR bandwidth is $2.38 \%$ (3.31$3.39 \mathrm{GHz}$ ) at $5 \mathrm{G}$ band.

\section{REFERENCES}

1. Garg, Ramesh, et al. Microstrip antenna design handbook. Artech house, 2001.

2. Eleftheriades, George V., and Keith G. Balmain, "Negativerefraction metamaterials: fundamental principles and applications," John Wiley \& Sons, 2005.

3. Ortiz, Noelia, Juan Carlos Iriarte, Gonzalo Crespo, and Francisco Falcone, "Design and implementation of dual-band antennas based on complementary split ring resonators." Waves in Random and Complex Media 25.3 (2015): 309-322.

4. Saurav, Kushmanda, Debdeep Sarkar, and Kumar Vaibhav Srivastava, "Dual-polarized dual-band patch antenna loaded with modified mushroom unit cell," IEEE Antennas and Wireless Propagation Letters, vol.13, pp.1357-1360, 2014.

5. Majedi, Mohammad Saeed, and Amir Reza Attari, "Dual-band resonance antennas using epsilon negative transmission line," IET 